\title{
CUIDADO PERSONAL Y COPATERNIDAD: COMENTARIO A LA SENTENCIA DE la CORTE SuPREMA DE CHILE DE 23 DE MAYO DE 2017 (ROL No 99.861-16)*
}

\author{
FABIOLA LATHROP GÓMEZ ${ }^{* *}$
}

\section{INTRODUCCIÓN}

El 23 de mayo de 2017, la Corte Suprema de Chile dictó un fallo que causó un importante revuelo social y jurídico' ${ }^{1}$. La prensa informó al respecto con frases como: "Histórico fallo de Corte Suprema da tuición de mellizos a su padre homosexual" 2 , pues sería esta la primera vez que este tribunal otorga el cuidado personal de dos niños a un padre de orentación homosexual, conociendo la circunstancia de que este se encuentra viviendo con su cónyuge del mismo sexo -con quien ha contraído matrimonio en Argentina-.

El fallo es relevante jurídicamente por dos razones. En primer lugar, como he señalado, la sentencia concede el cuidado personal de dos niños de tres años y medio a su padre - para que pasen a vivir con este y su pareja del mismo sexo-, sin realizar disquisiciones acerca de la orientación sexual del padre. La sentencia tiene como premisa la situación de igualdad en que se encuentran el padre y la madre, con independencia del sexo, género y orientación sexual que presentan; la determinación del interés superior de los hijos constituye la cuestión central de su análisis. La Corte Suprema solo señala que los jueces del fondo "tuvieron presente que la orientación sexual de los padres no es una consideración relevante

* Fecha de recepción: 31 de agosto de 2017.

Fecha de aceptación: 2 de noviembre de 2017.

** Licenciada en Ciencias Jurídicas y Sociales de la Universidad de Chile, Abogada, Doctora en Derecho por la Universidad de Salamanca. Profesora Asociada de la carrera académica ordinaria del Departamento de Derecho Privado de la Facultad de Derecho de la Universidad de Chile (Chile). Correo electrónico: flathrop@derecho.uchile.cl

1 Corte Suprema. 23 de mayo de 2017. Rol No 99.861-16, pp. 1-25. La decisión fue adoptada por la Cuarta Sala del máximo tribunal, integrada por el señor ministro Carlos Cerda F., la señora ministra Andrea Muñoz S. y el abogado integrante señor Álvaro Quintanilla P., quienes constituyeron el voto de mayoría; y por el ministro señor Ricardo Blanco H. y la ministra señora Gloria Ana Chevesich R., que conformaron el voto de minoría.

2 Teletrece (2017) Histórico fallo de Corte Suprema da tuición de mellizos a su padre homosexual. Disponible en: http://www.t13.cl/noticia/nacional/historico-fallo-corte-suprema-da-tuicion-mellizos-su-padre-homosexual [fecha de visita 11 de agosto de 2017]. 
para decidir acerca del cuidado personal de los hijos" 3 . En segundo lugar, la sentencia contribuye -sustancialmente- a fijar el sentido y el alcance de algunas de las disposiciones sobre cuidado personal de los hijos reformadas en 2013 mediante Ley 20.680; en especial, acerca de supuestas preponderancias de algunos criterios interpretativos por sobre otros mencionados en el artículo 225-2 del Código Civil.

\section{1) LOS HECHOS}

Los hechos son los siguientes ${ }^{4}$. Una pareja conformada por dos ciudadanos extranjeros que mantienen una relación de más de 18 años, radicada en Chile desde 2006, contrae matrimonio, el año 2012, en la ciudad de Buenos Aires, Argentina. En vista del anhelo de la pareja de ser padres y del propio deseo de ser madre de una mujer amiga -también extranjera- a quien ambos conocen en Chile, deciden someterse a un proceso de reproducción asistida. La mujer deja en manos del matrimonio la decisión de determinar quién sería el padre genético; acordando que el niño o nińa que naciera siempre tendría claro quién era tal progenitor, así como conocimiento de la orientación sexual del mismo. Estas personas están conformes, además, en que tendrían una familia no tradicional, con dos hogares, en la que todos participarían por igual en la crianza y educación del niño o niña que naciera.

Sin embargo, una vez confirmado el embarazo de mellizos, la madre biológica comunica al padre que no permitiría en forma alguna que el cónyuge de este participara en la crianza de los niños, porque no le reconocía calidad de "padre", desconociéndose así lo previamente acordado5. De este modo, al momento del nacimiento de los mellizos, la mujer solo

3 CS. Rol N 99.861-16, considerando segundo. Es de destacar que la sentencia de la Corte de Apelaciones de Santiago, citando el caso "Atala Riffo y niñas vs. Chile", comienza señalando que comparte con el juzgador de primera instancia que la orientación sexual de los padres no era una consideración relevante en el ordenamiento jurídico chileno a efectos de decidir sobre el cuidado personal de los hijos (considerando segundo). En efecto, ninguno de los fallos referidos a esa causa puso en duda las habilidades del padre varón para cuidar a sus hijos, teniéndose especialmente en cuenta que, en el caso de vivir con este, serían criados -también- por su pareja del mismo sexo, la que fue, además, escuchada como testigo en el juicio.

4 Esta descripción se basa en lo señalado en la sentencia de primera instancia así como en lo relatado por el abogado del padre demandante, en el seminario organizado por la Facultad de Derecho de la Universidad de Chile "Cuidado personal y copaternidad: comentario al reciente fallo de la Corte Suprema”, celebrado el 17 de agosto de 2017.

5 La madre desconoce el acuerdo señalando que las condiciones para la inseminación artificial fueron las siguientes: que hubiera exclusivamente una figura paterna y que los hijos se criaran en Uruguay desde los dos años o, como máximo, al empezar la escuela. Señala que no tiene problemas con que el cónyuge del padre de los niños sea parte de la familia; sin embargo, afirma que no es el padre; de hecho, reconoce que este cónyuge ha visto a los niños 
permitió al padre biológico visitar a los niños, siempre y cuando continuara haciéndose cargo de la totalidad de los gastos ocasionados por ellos.

En 2014, luego de dos meses de nacidos los niños, la madre informa al padre que viajaría a Uruguay, junto a los niños, por un mes. Ante la negativa del padre, la madre presenta una solicitud de autorización de salida del país. A instancias del tribunal, el padre autoriza la salida, mediando un acuerdo de régimen comunicacional, en el cual, entre otros aspectos, se señala que el cónyuge del padre participaría activamente de las "visitas" realizadas a los niños y de los viajes que se acordaba realizar a Uruguay. Pues bien, en uno de los viajes que se autorizaron, la madre no vuelve a Chile, ante lo cual se gatilla un juicio de sustracción internacional que finaliza ordenando el regreso al país de origen y residencia de los nińos.

Luego de una serie de conflictos respecto de los niños, el padre inicia un juicio de cuidado personal que termina resuelto a su favor por la Corte Suprema, el 23 de mayo de 2017. Esta Corte señala que los jueces de fondo tuvieron como hechos de la causa, los siguientes ${ }^{6}$ :

- "Ambos padres están interesados en mantener el cuidado de sus dos hijos menores de edad y no presentan inhabilidades para ejercerlo (...).

- La madre muestra un desempeño de competencias parentales en general competente, lo que facilitaría el enfrentamiento satisfactorio de las tareas básicas de cuidado y estimulación de los niños, propios de su carácter de madre, interferidas actualmente por la ansiedad en respuesta al estrés del conflicto existente. En sus competencias parentales vinculares y reflexivas se evalúa con un desarrollo básico; en las formativas y protectoras como competentes; y para la coparentalidad como insatisfactoria, pero con pronóstico positivo. Las vinculares están afectadas por ansiedad y depresión y muestra un estilo intrusivo, se adelanta a las necesidades, no logra discriminar sus necesidades versus las de sus hijos, pero tiene potencial.

- El padre aparece con sus competencias parentales vinculares con un desarrollo satisfactorio; las formativas, protectoras y reflexivas como competentes; y para el desarrollo de la coparentalidad como básica, pero con buen pronóstico, y desde un punto de vista técnico, garantizaría mejor la vinculación con el otro progenitor, si los nińos estuvieren a su cargo; y tiene mejor evaluación en el área de habilidades parentales, de empatía, y de diferenciación de necesidades entre los niños. No tiene antecedentes de depresión, es más bien reflexivo, 
propone buenos acuerdos y está llano a alcanzar acuerdos en pro del buen término del juicio.

- El conflicto familiar afecta a ambos padres en sus competencias de coparentalidad y aparece uno generado por el padre, en su intención de homologar a la madre con su pareja, lo que es fuente, en parte, de las tensiones, junto con el temor de ella de ser anulada en su calidad de tal cuando los niños están con el padre, sin saber muy bien cómo tolerar la angustia, a lo que se une su fuerte concepto de familia tradicional respecto a la no aceptación de la pareja del padre y la judicialización del conflicto familiar. Parte del proceso judicial ha generado en la madre confusión y ansiedad que le dificulta tener respuestas acertadas y empáticas en algunas ocasiones, lo que aparece afectándola, en parte, en las competencias calificadas como básicas, en particular, en las vinculares y reflexivas.

- Los tiempos laborales del padre son más flexibles que los de la madre (...)

- No hay ningún factor de riesgo de los nińos con la madre ni con el padre, ni existe inconveniente alguno que se queden al cuidado de uno u otro, tampoco se vislumbra alguno por ser criados por el padre biológico y su pareja del mismo sexo.

- Los niños se encuentran en un estado de salud física y mental normal, pero uno de los niños no presenta el mismo nivel de desarrollo que el otro y requeriría una atención especial de sus progenitores, donde la madre presenta competencias básicas, en especial por el tratamiento conjunto que da a ambos niños, sin diferenciar, todo frente a un padre más atento.

- El sistema de relación directa y regular existente consiste en que los niños viven con la madre durante la semana, y con el padre los viernes y sábados; pero este ha tenido dificultades para mantener las visitas con sus hijos, llegando al extremo el episodio que dio origen a la causa tramitada en Uruguay".

\section{2) SENTENCIA DE PRIMERA INSTANCIA QUE CONCEDE EL CUIDADO PERSONAL DE LOS NIÑOS A SU PADRE}

El fallo de primera instancia, de 22 de junio de 2016, emanado del Tercer Juzgado de Familia de Santiago (recaído en causa RIT C-37132015), concede el cuidado personal de ambos niños a su padre. El juez de la causa sostuvo que "lo más adecuado para la situación actual y futura de los niños, es poder compartir con ambos padres, pero como la hipótesis normativa chilena no consagra el cuidado personal compartido, salvo acuerdo de las partes, es que se resolverá que los niños, queden bajo la custodia del 
padre, por aplicación de los dispuesto en los artículos 222, 224 y 225 del Código Civil, pero garantizando a la madre un régimen comunicacional, tan amplio como en derecho corresponda"7 (considerando vigésimo).

El fallo de primera instancia describe latamente la prueba rendida, advirtiéndose, en múltiples ocasiones, que el padre demandante se encontraba, a juicio del sentenciador, en mejores condiciones para ejercer el cuidado personal de los mellizos. En efecto, señaló que los consejeros técnicos: "indican ambos que de acuerdo a los antecedentes agregados, principalmente informes periciales y en especial atención a los derechos de los niños, refieren que son de opinión que se entregue el cuidado de los hijos al padre, ello a fin de resguardar el interés superior de los niños, manteniendo visitas amplias con la madre, por ser el padre quien cuenta con mejores habilidades parentales, lo que fue referido e informado en forma unánime por todos los peritos que declararon en el juicio, y por ser este, quien mejor podría garantizar un régimen de relación directa y regular para con el padre no custodio, en este caso con la madre, ello tanto desde un punto de vista social, como psicológico"8. En concreto, se señala que la perito psicóloga que evaluó a los niños estimó que "no hay ningún riesgo en los niños, en ser criados, por la pareja homosexual" 9 .

Si bien esta decisión fue dictada estando vigente la nueva normativa introducida al Código Civil mediante Ley 20.680, de 21 de junio de

7 Tercer Juzgado de Familia de SAntiago. Sentencia de 22 de junio de 2016. Rit C-3713-2015, pp. 1-17, considerando vigésimo.

8 Tercer Juzgado de Familia de SAnTiago. RIT C-3713-2015, p. 11, considerando noveno. En el considerando décimo se añade que es el padre varón: "quien da mayores resguardos a los intereses y derechos de los niños, quien los ha cuidado más correctamente, quien resuelve mejor las dificultades que se presentan en la crianza de ellos, quien podría garantizar mejor la comunicación con el otro padre, y quien satisface mejor sus necesidades, tanto las económicas, como las afectivas, así como quien cuenta con mejores redes de apoyo, y también resulta obligatorio ver como los niños se relacionan con ellos, atendida su edad". Y en el considerando undécimo, que: "los niños, han sido cuidados por su madre, quien satisface sus necesidades, pero que tiene dificultades para distinguir entre las necesidades de cada niño en particular, lo que es necesario, toda vez que no presentan el mismo nivel de desarrollo, y en ocasiones ésta pone sus necesidades antes que las de los niños, teniendo en consideración lo declarado por los cinco peritos, tres psicólogos y dos asistentes sociales, quienes concluyen, independientemente de quien los presente, que la figura de la madre, no tiene el tratamiento adecuado en el área de coparentalidad, para reconocer a la figura del padre y menos la de su cónyuge, a quien intenta excluir, coparentalidad en la que el padre también presenta dificultades, pero en menor medida que la madre, concluyendo por ello, que sería desde un punto de vista técnico mejor garantizada la vinculación con el otro padre, si estos estuvieren a cargo del padre". En otros pasajes se señala, a propósito de la coparentalidad: "a diferencia de la madre que no genera ningún acuerdo, para con el otro padre" (considerando duodécimo); o bien, que el padre "podría hacerse cargo más personalmente de la crianza de los niños, atendido los tiempos laborales del padre, que resultan más flexibles que en la madre, quien declaró trabajar desde las 9:00 horas hasta las 19:00 horas, cuando declaró en calidad de parte en estrado" (considerando decimotercero).

9 Tercer Juzgado de Familia de SANTiago. RIT C-3713-2015, p. 13, considerando decimocuarto. 
2013, su texto contiene pasajes sustentados en normas derogadas. Así, señala que el padre "cuenta con mejores habilidades psicosociales que la madre para hacerse cargo de sus hijos, y porque existe causa calificada, que es que el padre técnicamente es la figura significativa y adecuado (sic) para los niños, que en atención a sus cualidades personales, requieren de una estabilidad"10. Y, más patente aún, citando un artículo derogado por la citada Ley 20.680: "en esta causa se escuchó a cinco peritos, un testigo, cónyuge de una de las partes, obligación contenida en el artículo 228 del código civil"11.

\section{3) Sentencia de la Corte de Apelaciones de Santiago que REVOCA EL FALLO DE PRIMERA INSTANCIA, OTORGANDO EL CUIDADO PERSONAL DE LOS NIÑOS A SU MADRE}

En fallo de 22 de noviembre de 2016, la Duodécima Sala de la Corte de Apelaciones de Santiago, revocó la decisión de primera instancia, sobre la base de una interpretación, a mi juicio, equívoca, de las reglas y principios del Código Civil en materia de cuidado personal de niños, niñas y adolescentes $^{12}$.

En efecto, la sentencia recaída en apelación sostuvo que ambos padres (padre genético y madre biológica) eran aptos para el cuidado de los niños: "por lo que lo mejor sería el régimen compartido de cuidado personal" y que, en la opción de tomar una decisión, no existía "una causal grave calificada para alterar el estándar legislativo priorizado para la tutela del interés superior del niño en la ponderación de criterios"13.

Así, esta sentencia fija, erradamente, una especie de regla supletoria para la falta de acuerdo de los padres sobre el cuidado personal de sus hijos. Esta interpretación se detecta en los siguientes pasajes del fallo. En primer lugar, al referirse al inciso tercero del artículo 225 del Código Civil, señala que la norma que reza "los hijos continuarán bajo el cuidado personal del padre o madre con quien estén conviviendo", mira a "la estabilidad de la situación del hijo, en vistas del apego y del arraigo de éste, pero proyectada en el tiempo"14. En segundo lugar, y más directamente aun, continúa afirmando que la conjugación de los artículos 225 inciso tercero y cuarto y 225-2 del Código Civil,

\footnotetext{
10 Tercer Juzgado de Familia de SANTIAgo. RIT C-3713-2015, pp. 13-14, considerando decimosexto.

11 Tercer Juzgado De Familia De SAnTiago. RIT C-3713-2015, p. 15, considerando decimonoveno.

12 Corte de Apelaciones de Santiago. Sentencia de 22 de noviembre de 2016. Rol N 1889-2016 (Familia), pp. 1-13.

13 CA SANTIAgO. Rol No 1889-2016 (Familia), p. 10, considerando noveno.

14 CA SANTiago. Rol N 1889-2016 (Familia), p. 4, considerando quinto.
} 
conllevaba a observar que "el legislador nuevamente tenía prioridad de regulación" luego de la reforma de 2013. Es así que señala que "la ley interpreta y concretiza el principio de interés superior del niño, regulando directamente la situación de la titularidad y ejercicio del cuidado personal en el inciso tercero del artículo 225 del Código Civil, priorizando la estabilidad material y espiritual del hijo, por sobre otros criterios, para efectos de proteger el apego al padre con quien convive, y el arraigo a su hogar, y a afectos de su desarrollo de manera estable en el tiempo"15.

La Corte de Apelaciones de Santiago afirmó que de los informes periciales se desprendía que ambos padres presentaban un "nivel relativamente similar" de habilidades parentales, insuficiente para "romper el estándar legalmente priorizado de estabilidad" referido. De esta forma, la sentencia sostiene que "las deficiencias en las competencias que nota la sentencia a quo y las pericias psicológicos (sic) atinente a la madre y en parte al padre, son mejorables mediante la terapia de fortalecimiento de habilidades parentales, por lo que no se ve una necesidad de afectar la estabilidad de la situación de los niños, cuestión privilegiada por el legislador" 16 .

Como se puede apreciar, la Duodécima Sala de la Corte de Apelaciones de Santiago interpreta la nueva normativa del Código Civil en materia de cuidado personal, afirmando que la Ley 20.680, de 21 de junio de 2013, habría consagrado un criterio prioritario a valorar en la atribución de tal cuidado, sobre la base de los elementos mencionados en el artículo 225-2 y lo prescrito en el inciso cuarto del artículo 225, todos del Código Civil; y, particularmente, en el inciso tercero de esta última norma, que señala que: "A falta del acuerdo del inciso primero, los hijos continuarán bajo el cuidado personal del padre o madre con quien estén conviviendo". La Sala afirma que existiría un "estándar legislativo priorizado" para la satisfacción del interés superior de los hijos, consistente en la "estabilidad material y espiritual" de los niños.

El voto de minoría de la sentencia de la Corte Suprema (sentencia que comentaré en el apartado siguiente) reafirma esta interpretación al sostener que "la controversia fue resuelta al amparo de un principio que la doctrina sobre la materia denomina de estabilidad del niño, niña o adolescente, que postula que corresponde mantener la situación de hecho en que se encuentra en cuanto sea beneficioso para él, lo que implica proteger su interés superior, y por lo mismo, no es pertinente modificar la atribución del cuidado personal vigente (Lathrop G., Fabiola, El cuidado personal y la relación directa y regular. Estudio exploratorio en los tribunales de familia de la Región Metropolitana, Santiago, Chile, LegalPublishing, 2013, p. 174)"17.

15 CA SANTiago. Rol N 1889-2016 (Familia), p. 5, considerando sexto.

16 CA SANTIAGO. Rol N 1889-2016 (Familia), pp. 9-10, considerando octavo.

17 Díaz y Duque se refieren a la estabilidad que el legislador de 2013 habría protegido con esta nueva regla supletoria, pero sin llegar a decir que es un principio ni menos una priorización: 
$\mathrm{Al}$ respecto, merece la pena señalar que tal principio ni doctrina existen; lo que se desarrolla en la publicación que el voto de minoría cita, es una cierta tendencia de parte de los tribunales -previa, por cierto, a la reforma del año 2013- a considerar la estabilidad de los hijos como uno de los elementos que contribuyen a determinar el interés superior del hijo en el caso en concreto.

A mi entender, esta interpretación no se ajusta a los principios y a las reglas establecidas, a partir del año 2013, para determinar cuál de los progenitores satisface mejor el interés superior de los nińos en contexto de juicios sobre cuidado personal. En realidad, la sentencia de la Corte de Apelaciones, en vez de establecer qué padre o madre satisface de mejor manera el interés superior de los niños, intenta descartar la existencia de inhabilidades en la madre, reproduciendo, de esta forma, la normativa anterior a 2013. En efecto, no obstante citar los resultados de los informes presentados en primera instancia, en los que se seńala que la madre tiene competencias parentales claramente inferiores al padre, la sentencia estima que las habilidades de ambos progenitores son similares y que, atendido este "estándar legal priorizado" constituido por la "estabilidad" de los nińos, es mejor que estos continúen bajo el cuidado personal de la madre.

La sentencia otorga preponderancia a la "estabilidad" de los niños, por sobre otros criterios y circunstancias que, conforme al inciso primero de artículo 225-2 del Código Civil, debe considerar y ponderar conjuntamente. A criterio de los sentenciadores, esta estabilidad se restringe, exclusivamente, a un elemento puramente fáctico y físico, cual es que ambos niños continúen viviendo con su madre. De esta forma, en vez de determinar cuál de los progenitores es el más apto para detentar el cuidado personal de los niños, atendiendo al interés superior de estos últimos, la sentencia busca detectar una inhabilidad en la madre para confirmar o revocar el fallo de primera instancia, reproduciendo, así, una regla de preferencia que ha sido derogada mediante Ley 20.680, de 21 junio de 2013.

En efecto, bajo la vigencia del antiguo artículo 225 inciso primero del Código Civil, la ley otorgaba preferencia a la madre para el cuidado personal de los hijos si los padres vivían separados; salvo que, conforme al antiguo inciso tercero del artículo 225 del mencionado cuerpo legal, por maltrato, descuido u otra causa calificada, y siempre que el interés del hijo lo hiciere indispensable, el juez lo entregare al otro de los progenitores. A mayor abundamiento, la causa calificada que el legislador refería

\footnotetext{
"Hoy la regla de atribución supletoria deja a los padres en igualdad de condiciones, priorizando claramente la estabilidad de los hijos, buscando mantener la continuidad en la vida de ellos (la que se ha visto alterada con la separación de los padres)". DíAz CARONNA, Ximena y DUQUE VILlA, José (2016) "Cuidado personal compartido. Una modificación sustantiva y sus repercusiones procesales”, en VV.AA.: Derecho procesal de familia a 10 años de la reforma. Santiago de Chile: Libromar, pp. 235-281, p. 270.
} 
era probada a través de circunstancias que acreditaran inhabilidad física o moral de la madre (recurriendo al artículo 226 del Código Civil) ${ }^{18}$.

Sin embargo, el actual texto del artículo 225 del Código Civil, en observancia a los principios de interés superior del niño, de igualdad y de corresponsabilidad parental, permanece neutro frente al sexo y género de los progenitores, al no dar preferencia a ninguno de los dos para determinar quien ejerce el cuidado personal de sus hijos. De esta forma, asumiendo estándares internacionales, nuestra ley obliga al juez a decidir sobre la atribución y ejercicio del cuidado personal teniendo como criterio rector la satisfacción plena e integral del interés superior del niño. En este sentido, conforme al establecimiento fidedigno de la Ley 20.680, las modificaciones introducidas en el ańo 2013 persiguieron fortalecer el acuerdo de los progenitores una vez producida la separación, abandonando criterios de preferencia no fundados en el interés de los hijos; así, la regla supletoria contenida actualmente en el inciso tercero del artículo 225 del Código Civil -que entrega, a falta de acuerdo de los padres, el cuidado personal del hijo al padre o madre que esté conviviendo con él- se originó en la Comisión Mixta durante el Tercer Trámite Constitucional de la reforma, y tuvo por objeto resolver una situación de hecho sobreviniente a la separación de los progenitores, sin que, necesariamente, deba vinculársele con la estabilidad de los hijos, cuestión de fondo que solo debiera discutirse en una instancia en que los progenitores $-\mathrm{y}$, en su caso, un tercero- desee alterar dicha regla fáctica ${ }^{19}$.

Así ha quedado claro en la doctrina especializada desarrollada sobre esta regla: “(...) la actual norma no prefiere a un progenitor en particular, sino que atiende a una situación de hecho, dado que en todo momento el cuidado personal de los hijos debe estar radicado en alguien" ${ }^{20}$. La estabilidad de los hijos, en los términos actuales de los artículos 225 y siguientes del Código Civil, se encuentra mencionada en la definición del cuidado personal compartido (artículo 225 inciso segundo), y se refiere a los estándares y seguridades que la modalidad en que se desarrollará la

18 Este artículo establece que en caso de inhabilidad física o moral de ambos padres, el juez puede confiar el cuidado personal de los hijos a la persona o personas que se estime competentes, velando primordialmente por el interés superior del niño conforme a los criterios del artículo 225-2.

19 Véase la "Historia de la Ley 20.680" elaborada por la Biblioteca del Congreso Nacional, disponible en www.bcn.cl. En ella consta que la actual redacción del mencionado inciso tuvo su origen en una propuesta del Servicio Nacional de la Mujer, recogiendo las preocupaciones de los parlamentarios en orden a entregar una solución cuando no hubiere acuerdo de los padres.

Biblioteca del Congreso Nacional (2008) Historia de la Ley 20.680. Inédito. Disponible en: www.bcn.cl/obtienearchivo?id=recursoslegales/10221.3/44153/7/HL20680.pdf [fecha de visita 11 de agosto de 2017] pp. 664 y 700.

20 ACUÑa SAn Martín, Marcela (2016) "Efectos de la Filiación”. En Del Picó Rubio, Jorge (Director): Derecho de Familia. Santiago de Chile: Thomson Reuters, pp. 475-538, p. 490. 
residencia del hijo bajo tal régimen, debe otorgar. En suma, la ley no ha priorizado la estabilidad material y espiritual del hijo por sobre otros criterios -como lo afirma erróneamente la sentencia de la Duodécima Sala de la Corte de Apelaciones de Santiago, en su considerando sexto-, ya que la mejor garantía de dicha estabilidad debe emanar de los criterios y circunstancias que menciona el artículo 225-2 del Código Civil, en especial, sus letras d) y e), en atención a la consideración primordial que constituye el interés superior del niño ${ }^{21}$.

A mayor abundamiento, en cumplimento a la Observación General número 14, de 2013, del Comité de Derechos del Niño, el Estado chileno ha elaborado "una lista de elementos no exhaustiva ni jerárquica que podrian formar parte de la evaluación del interés superior del niño que lleve a cabo cualquier responsable de la toma de decisiones que tenga ante si ese cometido" (párrafo 50, énfasis añadido). Así, los criterios contenidos en el actual artículo 225-2 del Código Civil no constituyen meras orientaciones para el juez, sino que deben ser confrontados con las circunstancias específicas del caso concreto que está llamado a decidir, en el entendido que, de esa forma, se satisface la directriz primordial vigente, esto es, el interés superior del niño. Por su parte, no existe preferencia legal $-y$ no podría haberla a la luz de la señalada Observación- por alguno de dichos elementos (a diferencia de lo que la sentencia de la Corte de Apelaciones de Santiago sostiene en su considerando sexto), toda vez que el único criterio rector es el interés superior del niño. Así lo ha seńalado la doctrina más reciente que ha interpretado dicho precepto: "Estos criterios y circunstancias deben ser considerados y ponderados conjuntamente, lo que impide al juez basar su decisión en una única circunstancia (...)"22.

21 Artículo 225-2 del Código Civil: "En el establecimiento del régimen y ejercicio del cuidado personal, se considerarán y ponderarán conjuntamente los siguientes criterios y circunstancias:

a) La vinculación afectiva entre el hijo y sus padres, y demás personas de su entorno familiar.

b) La aptitud de los padres para garantizar el bienestar del hijo y la posibilidad de procurarle un entorno adecuado, según su edad.

c) La contribución a la mantención del hijo mientras estuvo bajo el cuidado personal del otro padre, pudiendo hacerlo.

d) La actitud de cada uno de los padres para cooperar con el otro, a fin de asegurar la máxima estabilidad al hijo y garantizar la relación directa y regular, para lo cual considerará especialmente lo dispuesto en el inciso quinto del artículo 229.

e) La dedicación efectiva que cada uno de los padres procuraba al hijo antes de la separación y, especialmente, la que pueda seguir desarrollando de acuerdo con sus posibilidades.

f) La opinión expresada por el hijo.

g) El resultado de los informes periciales que se haya ordenado practicar.

h) Los acuerdos de los padres antes y durante el respectivo juicio.

i) El domicilio de los padres.

j) Cualquier otro antecedente que sea relevante atendido el interés superior del hijo".

ACUÑA (2016) 497. 


\section{4) Sentencia de la Corte Suprema Que CASA El fallo de la CorTe DE APElaCiOnes de SANTIAgo, CONCEDIENDO EL CUIDADO PERSONAL DE LOS NIÑOS A SU PADRE}

La sentencia de la Corte Suprema de Chile, de 23 de mayo de 2017, sienta jurisprudencia por las razones que explicaré a continuación.

En primer lugar, determina el alcance y el contenido del inciso tercero del artículo 225 del Código Civil, como regla supletoria: "Que, contrario a lo que sostiene el fallo impugnado, la regla del inciso $3^{\circ}$ del artículo 225 del Código Civil fue introducida por la ley 20.680 como una regla supletoria y provisoria, para el caso de separación de los padres, cuando no existiere acuerdo respecto de cuál de ellos tendría el cuidado personal de los hijos menores, atendida la eliminación de la regla de atribución legal que establecía una preferencia en favor de la madre en tal evento. En términos prácticos, la regla opta por mantener la situación de hecho que se verifica en tal momento, dejando el cuidado personal en quien estuviere conviviendo con los hijos a esa fecha, mientras no exista una decisión judicial al respecto" 23 .

La sentencia de la Corte Suprema aclara que el interés superior del hijo es el criterio determinante, descartando cualquier priorización de criterios legales: "el interés superior del niño es el único elemento que ha de primar a la hora de decidir sobre el cuidado personal del hijo, con lo cual se pone fin al criterio que todavía solía invocarse - pese a las modificaciones introducidas por la ley 19.585- y que giraba en torno la inhabilidad de la madre o del padre para ejercer dicho cuidado. En consonancia con aquello, se establecieron en el artículo 225-2, determinados criterios y circunstancias que los jueces "considerarán y ponderarán conjuntamente" para decidir a cuál de los padres atribuir el cuidado personal del niño o niña, sin que ninguno de ellos tenga prioridad ni menos deban subordinarse a la regla provisoria del inciso $3^{\circ}$ del articulo $225^{\prime \prime 24}$.

La sentencia de la Corte Suprema es enfática al señalar que "los jueces del fondo cometen un error de derecho al interpretar la norma en la forma en que lo han hecho (...), en el sentido de apreciar los distintos elementos probatorios bajo la mirada de si son suficientes para derrotar el criterio legal preferido, o alterar el estándar legislativo priorizado, en circunstancias que, como se ha dicho, no existe tal priorización o preferencia legal, en la medida que lo único que interesa es desentrañar con quién los niños habrán de estar mejor" 25 .

\footnotetext{
23 CS. Rol No 99.861-16, p. 14, considerando cuarto.

24 CS. Rol No 99.861-16, p. 14, considerando cuarto.

25 CS. Rol No $99.861-16$, p. 15 , considerando quinto.
} 
Finalmente, señala que "la sentencia vuelve a reiterar el concepto equivocado acerca de la preferencia legal en cuanto al cuidado personal, $e$ incluso agrega otro criterio que fue derogado por la ley 20.680, cual es el de la necesidad de una "causa grave calificada", para alterar la situación previa, lo que significa mantener una barrera o estándar que la legislación actual no prevé y que, precisamente desechó, para privilegiar por sobre todo, el interés superior del niño, sin exigir que la situación deba encontrarse en el límite"26.

De esta forma, la Corte Suprema sienta, a mi juicio, la interpretación correcta, en el sentido de que solo el interés superior del niño es el criterio clave para determinar al titular del cuidado personal de los hijos; pueden existir elementos que, atendido el caso en concreto, sean más o menos relevantes para fijar tal interés -como el de la estabilidad material y psicológica-, pero, en ningún caso, debe entenderse que los artículos 225 y 225-2 del Código Civil privilegian alguna circunstancia fáctica por sobre otras consideraciones o que establecen alguna vinculación directa entre la estabilidad del hijo y la realización de su interés superior.

\section{CONCLUSIONES}

La sentencia de la Corte Suprema refuerza los principios de igualdad y no discriminación por razón de orientación sexual, protegiendo el derecho a la vida familiar del padre demandante y, muy especialmente, el derecho a la vida familiar de los niños. A la luz del interés superior del nińo, la Corte Suprema determina que el padre genético presenta mayores y mejores habilidades parentales en relación a la madre. La sentencia, sin referirse expresamente a estos principios y derechos -salvo el de interés superior-, reconoce, indirectamente, que dos personas del mismo sexo pueden cuidar de menores de edad. En efecto, si bien entrega el cuidado personal a quien es el padre genético de los niños -con quien existe filiación paterna determinada-, es sabido por los sentenciadores que la pareja del mismo sexo de tal progenitor es, en la realidad familiar, un copadre para los niños. Más allá de que la filiación paterna está determinada a favor del demandante, la Corte Suprema favorece la crianza de dos menores de edad por dos personas del mismo sexo, en el entendido de que en ese hogar existen mejores garantías de corresponsabilidad parental conjuntamente con la madre y de favorecimiento de una relación directa y regular con esta.

Por otro lado, la sentencia de la Corte Suprema contribuye -sustancialmente- a fijar el sentido y el alcance de algunas de las disposiciones

26 CS. Rol No 99.861-16, p. 15, considerando quinto. 
sobre cuidado personal de los hijos reformadas en 2013 mediante Ley 20.680; en especial, acerca de supuestas preponderancias de algunos criterios interpretativos por sobre otros mencionados en el artículo 225-2 del Código Civil.

La interpretación de la Corte de Apelaciones de Santiago, efectuada en la sentencia de 22 de noviembre de 2016, no se ajustó a los principios y a las reglas establecidas, a partir del año 2013, para determinar cuál de los progenitores satisface mejor el interés superior de los niños en contexto de juicios sobre cuidado personal. En vez de establecer qué padre o madre satisface de mejor manera el interés superior de los niños, intentó descartar la existencia de inhabilidades en la madre, reproduciendo la normativa anterior al año 2013. La Corte de Apelaciones de Santiago otorgó preponderancia a la estabilidad de los niños, por sobre otros criterios y circunstancias que, conforme al inciso 1 del artículo 225-2 del Código Civil, más bien deben considerarse y ponderarse conjuntamente.

Las modificaciones introducidas mediante la Ley 20.680 persiguieron fortalecer el acuerdo de los progenitores, abandonando criterios de preferencia no fundados en el interés de los hijos. La regla supletoria del inciso 3 del artículo 225 del Código Civil -que entrega, a falta de acuerdo, el cuidado personal del hijo al padre o madre que esté conviviendo con él- tuvo por objeto resolver una situación de hecho sobreviniente a la separación de los progenitores, sin que, necesariamente, deba vinculársele con la estabilidad de los hijos.

Finalmente, no es menos importante advertir que tanto el fallo de primera como de segunda instancia, ponen de manifiesto que el legislador no permite a la autoridad judicial el establecimiento de un régimen de cuidado personal compartido -reservado en la letra del artículo 225 del Código Civil solo para situaciones de acuerdo entre los progenitores-; sin perjuicio de la aprobación que pueda dar a una mediación, transacción o conciliación ${ }^{27}$. Ello, no obstante señalar, expresamente, que esta hubiera sido la alternativa más adecuada para los niños. Esta cuestión pone de manifiesto cómo el legislador de 2013, al menos en la letra de la ley, ha

27 En este sentido, ACUÑa (2016) 497; y DíAZ y DUQUe (2016) 259. El Tribunal Constitucional chileno se ha referido a esta cuestión señalando que "Que si bien puede haber otras opciones legislativas diversas a las establecidas en el inciso tercero del artículo 225 del Código Civil, la norma vigente no parece desproporcionada ni irracional' (sentencia de 16.06.15, Rol 2699-14, considerando decimoséptimo). En todo caso, se advierte doctrina contraria a esta opción del legislador de descartar el establecimiento del cuidado personal compartido judicialmente contra la oposición de alguno de los progenitores. Así, ILlANES, Alejandra (2015) "Incoherencias del régimen de custodia compartida introducido por la Ley 20.680 con los principios orientadores de la reforma”. En Departamento de Derecho Privado (editor): Estudios de Derecho Civil XI, Jornadas Nacionales de derecho Civil Concepción, 2015. Santiago de Chile: Thomson Reuters, pp. 139-152, p. 143: “(...) hacerlo depender de la voluntad de un progenitor, normalmente su actual custodio, importa per se un atentado al interés superior del niño (...)". 
limitado desproporcionadamente las facultades decisorias del juez, permitiéndole establecer el cuidado personal de los hijos solo al padre o a la madre -no a ambos-. Esta es una problemática que escapa al objeto de este comentario, de manera que esta autora deja solamente esbozada esta crítica.

\section{BIBLIOGRAFÍA}

Acuña San Martín, Marcela (2016) "Efectos de la Filiación”. En Del Picó Rubio, Jorge (Director): Derecho de Familia. Santiago de Chile: Thomson Reuters, pp. 475-538.

Díaz Caronna, Ximena y Duque Villa, José (2016) "Cuidado personal compartido. Una modificación sustantiva y sus repercusiones procesales". En VVAA: Derecho procesal de familia a 10 años de la reforma. Santiago de Chile: Libromar, pp. 235-281.

Illanes Valdés, Alejandra (2015) "Incoherencias del régimen de custodia compartida introducido por la Ley 20.680 con los principios orientadores de la reforma”. En Departamento de Derecho Privado (editor): Estudios de Derecho Civil XI, Jornadas Nacionales de derecho Civil Concepción, 2015. Santiago de Chile: Thomson Reuters, pp. 139-152. 